\title{
Ultra Performance Liquid Chromatography Tandem Mass Spectrometric Method Development and Validation for Determination of Neratinib in Human Plasma
}

\author{
Tanveer A. Wani ${ }^{\mathrm{a}, \star}$, Seema Zargar ${ }^{\mathrm{b}}$ and Ajaz Ahmad \\ ${ }^{a}$ Department of Pharmaceutical Chemistry, College of Pharmacy, King Saud University, P.O. Box 2457, Riyadh 11451, Saudi Arabia. \\ ${ }^{b}$ Department of Biochemistry, College of Science, King Saud University, P.O. Box 22452, Riyadh 11451, Saudi Arabia. \\ ${ }^{c}$ Department of Clinical Pharmacy, College of Pharmacy, King Saud University, Riyadh, 11451, Saudi Arabia.
}

Recieved 13 January 2015, revised 30 March 2015, accepted 1 April 2015.

\begin{abstract}
This study was designed to develop and validate a UPLC-MS/MS method for quantification of neratinib in human plasmsa. Neratinib is an irreversible tyrosine kinase inhibitor against the pan-ErbB (ErbB-1, -2, -4) receptor. UPLC-MS/MS is an excellent analytical methodology for rapid biomedical analysis, decreasing the time for analysis and maintaining good efficiency. Crizotinib was used as internal standard (IS). Samples where extracted by plasma protein precipitation (PPT) procedure with acetonitrile and methanol and analysis was performed on a $\mathrm{C}_{18}$ Acquity UPLC $\mathrm{BEH}^{\mathrm{TM}}$ column. The ion transitions where recorded in positive ion multiple reaction monitoring mode $m / z 557.51 \rightarrow 112.17$ for neratinib and $m / z 450.0 \rightarrow 260.0$ for IS. The mobile phase used was methanol:water: formic acid $(70: 30: 0.1 \%, \mathrm{v} / \mathrm{v} / \mathrm{v})$ with a flow rate of $0.3 \mathrm{~mL} \mathrm{~min}^{-1}$. The linearity of the assay was found to be 4-500 $\mathrm{ng} \mathrm{mL}^{-1}$ for neratinib in human plasma with lower limit of quatification of $4 \mathrm{ng} \mathrm{mL}^{-1}$. The intra- and inter-assay precision relative standard deviations did not exceed 10.99 and mean extraction recovery was found to be $69.12 \pm 3.58$.
\end{abstract}

KEY WORDS

Neratinib, UPLC, LC-MS/MS, pharmacokinetic study, human plasma.

\section{Introduction}

In controlling critical cellular activities such as the cell migration, cell cycle, cell survival and metabolism, cell differentiation and proliferation, the receptor tyrosine kinase plays a very important role. ${ }^{1}$ In various cancers hyperactivation of epidermal growth factor receptor (EGFR) family of receptor tyrosine kinases was observed and elevated levels of ErbB-2 and poor prognosis in (approximately) $30 \%$ cases of breast cancer is correlated with over-expression..$^{2-4}$ Monotherapy with transtuzumab $b^{4,5}$ which is the standard treatment for ErbB-2-positive breast cancer provides only $15 \%$ response rates, where as a combination of transtuzumab with paclitaxel or chemotherapy increases the success rate to $41 \%$ and $50 \%$, respectively. ${ }^{5-6}$ The most common problem with transtuzumab is the development of resistance. ${ }^{7}$ Neratinib (NTB) is a low molecular weight, potent, irreversible inhibitor of EGFR, HER2 and HER4 tyrosine kinase activity ${ }^{2,8-10}$ and has exhibited promising preclinical activity alone or in with combination pactitaxel or transtuzumab against HER2-overexpressing cell lines. ${ }^{8,11-13}$ NTB is currently undergoing several phase three clinical trials. ${ }^{14,15}$

In HER2-positive breast cancer patients with innate and acquired trastuzumab resistance NTB was found to be an effective anti-HER2 therapy alternative which counteracted the resistance. Trastuzumab in comination with neratinib exhibit a synergistic effect on each other compared to the use of either of the two drugs alone. ${ }^{16}$

After a single oral dose of 120-800 mg of NTB in healthy subjects in a fasting state the peak plasma NTB concentration (tmax) was found to be $4-7 \mathrm{~h}$, with a half-life of approximately $9-17 \mathrm{~h} .{ }^{17}$

* To whom correspondence should be addressed. E-mail: tanykash@yahoo.co.in
Literature review revealed a single publication regarding the determination of NTB in human plasma samples using high performance liquid chromatography mass spectrometry/mass spectrometry (HPLC-MS/MS) methods. ${ }^{18}$ In this report, conventional column (Genesis $\mathrm{C}_{18}$ column $(50 \times 2.1 \mathrm{~mm}, 4 \mu \mathrm{m}$ particle size) was used, whereas in our study $\left(\mathrm{C}_{18}\right.$ Acquity UPLC BEH ${ }^{\mathrm{TM}}$ column $2.1 \times 50 \mathrm{~mm} 1.7 \mu \mathrm{m}$ particle size) was used along with an UPLC-MS/MS system, which resulted in very low flow rate and faster analysis without affecting the sensitivity of the method. Since, the pharmacokinetic studies necessitates a drug assay that is simple, selective, economical, requires small sample volume, and has rapid turnaround time, the present paper bears improvement over the reported methods. ${ }^{19}$

UPLC is a new category of separation science which builds upon well-established principles of liquid chromatography, The column used has sub- $2 \mu \mathrm{m}$ porous particles and can operate at high mobile phase linear velocities thus producing significant reduction in time for separation and consumption of solvents. Application of the UPLC system results in a three-fold decrease in analysis time to conventional high-performance liquid chromatography using $3 \mu \mathrm{m}$ particle size columns and a nine times decrease in time compared to $5 \mu \mathrm{m}$ particle size columns. ${ }^{20-25}$ Acquity UPLC columns contain hybrid X-Terra sorbent, which utilizes a bridged ethyl siloxane/silica hybrid (BEH) structure, ensures column stability under high pressure and a wide $\mathrm{pH}$ range (1-12). ${ }^{25}$

In all the documented references, no validated UPLC-MS/MS method has been reported for the determination of NTB using in human plasma. Therefore, in this study, a validated UPLC-MS/MS method was developed and validated for analysis of NTB 
in human plasma. The proposed method is simple, cost-effective and rapid for the quantification of NTB in human plasma.

\section{Experimental}

\subsection{Materials and Methods}

NTB was obtained from Weihua Pharma Co., Limited, Zhejiang, China. Crizotinib was purchased from Tocris Bioscience (Shanghai, China). Methanol and acetonitrile (HPLC-grade), and ammonium acetate were procured from Winlab Laboratory (London, UK), and formic acid was procured from BDH Laboratory(Poole Dorset, UK). Other chemicals used in the study were of analytical grade. Human plasma was obtained from normal healthy volunteers at King Khalid University Hospital (Riyadh, Saudi Arabia), and ethical approval was obtained from the institutional review board of the King Khalid University Hospital (approval no. 14/3087/IRB). The samples were kept frozen at $-80{ }^{\circ} \mathrm{C}$ until analysis. Milli Q advantage $(0.22 \mu \mathrm{m}$, Millipore, Moscheim Cedex, France) water was used to prepare the aqueous solutions.

\subsection{Chromatography and Tandem Mass Spectrometry Systems}

The chromatopraphy was performed using an Acquity UPLC system (Waters Corp., Milford, MA, USA) equipped with a temperature-controlled sample and column compartments and coupled to Acquity triple quadrupole (TQD) tandem mass spectrometer (Waters Corp., Milford, MA, USA). Chromatographic separations were executed on a $2.1 \times 50 \mathrm{~mm} \mathrm{C} \mathrm{C}_{18}$ column packed with $1.7 \mu \mathrm{m}$ particles (ACQUITY UPLC BEH Waters) capable of bearing pressure of 15000 psi. Mobile phase was methanol: water:formic acid in the ratio (70:30:0.1 \%, v/v/v) with a flow rate of $0.3 \mathrm{~mL} \mathrm{~min}^{-1}$.

Detection of NTB and the IS was carried out by multiple reaction monitoring (MRM) using mass-to-charge $(\mathrm{m} / \mathrm{z})$ transitions of $557.29 \rightarrow 112.17$ for NTB (Fig. 1), and $450.0 \rightarrow 260.0$ for crizotinib (IS), with a dwell time of 0.0146 seconds. The capillary voltage for the ESI source, the cone voltages and collision energy for NTB and IS were optimized. The UPLC-MS/MS system was controlled by Mass Lynx software (SCN 805; Version 4.1, from Waters USA).

\subsection{Quality Control Samples and Calibration Standards}

Standard stock solutions of $1 \mathrm{mg} \mathrm{mL}^{-1}$ were prepared in methanol for both NTB and crizotinib. The stock solution of NTB was serially diluted to prepare working standards in the required concentration range with methanol. The calibration standards for NTB were prepared by spiking plasma with working standard solutions to yield calibration range from 4 to 500 $\mathrm{ng} \mathrm{mL} \mathrm{m}^{-1}(4,8,16,32,64,128,256$, and 500). The quality control (QC) sample solutions for NTB were separately prepared in methanol similarly as calibration standards at four different levels: $4 \mathrm{ng} \mathrm{mL}{ }^{-1}$ lower limit of quantitation (LLOQ), $12 \mathrm{ng} \mathrm{mL}^{-1}$ low quality control (LQC) (LQC, within three times of the LLOQ), $200 \mathrm{ng} \mathrm{mL}^{-1}$ middle quality control (MQC) and $400 \mathrm{ng}$ $\mathrm{mL}^{-1}$ high quality control (HQC). working standard solution for internal standard was prepared from crizotinib standard stock solution $\left(1 \mathrm{mg} \mathrm{mL}^{-1}\right)$ in methanol to get $1 \mu \mathrm{g} \mathrm{mL}^{-1}$.

\subsection{Sample Preparation}

To $200 \mu \mathrm{L}$ of plasma sample was added $10 \mu \mathrm{L}\left(1 \mu \mathrm{g} \mathrm{mL} \mathrm{L}^{-1}\right)$ of IS with the exception of the blank sample where no IS was added. These samples were vortexed for a period of 30 seconds after which $200 \mu \mathrm{L}$ of methanol were added and vortex mixed again for another 30 seconds. After vortexing, a further $500 \mu \mathrm{L}$ of acetonitrile were added to the sample tube. The resulting mixture was again vortexed for a period of $1.5 \mathrm{~min}$ and cold centrifuged at $10000 \mathrm{rpm}$ for $10 \mathrm{~min}$. The supernatant fluid was separated in a glass tube and evaporated to dryness using TurboVap LV evaporator (Model: C103199, Biotage, USA) at $40{ }^{\circ} \mathrm{C}$ under a gentle nitrogen stream. The residue was reconstituted with $200 \mu \mathrm{L}$ of mobile phase and transferred to UPLC vials. $5 \mu \mathrm{L}$ sample volumes were subjected for the analysis by UPLC-MS/MS in MS/MS mode.

\subsection{Validation of the Bioanalytical Method}

The method was validated as per US-FDA and EMEA guidelines in human plasma. ${ }^{26,27}$ To evaluate linearity, an eight-point standard plasma calibration curve $\left(4-500 \mathrm{ng} \mathrm{mL}^{-1}\right)$ was prepared and assayed in triplicate on three separate days. Peak area ratio of the NTB to internal standard were used for the construction of calibration curves. The curve fitting was achieved with $1 / x^{2}$ as

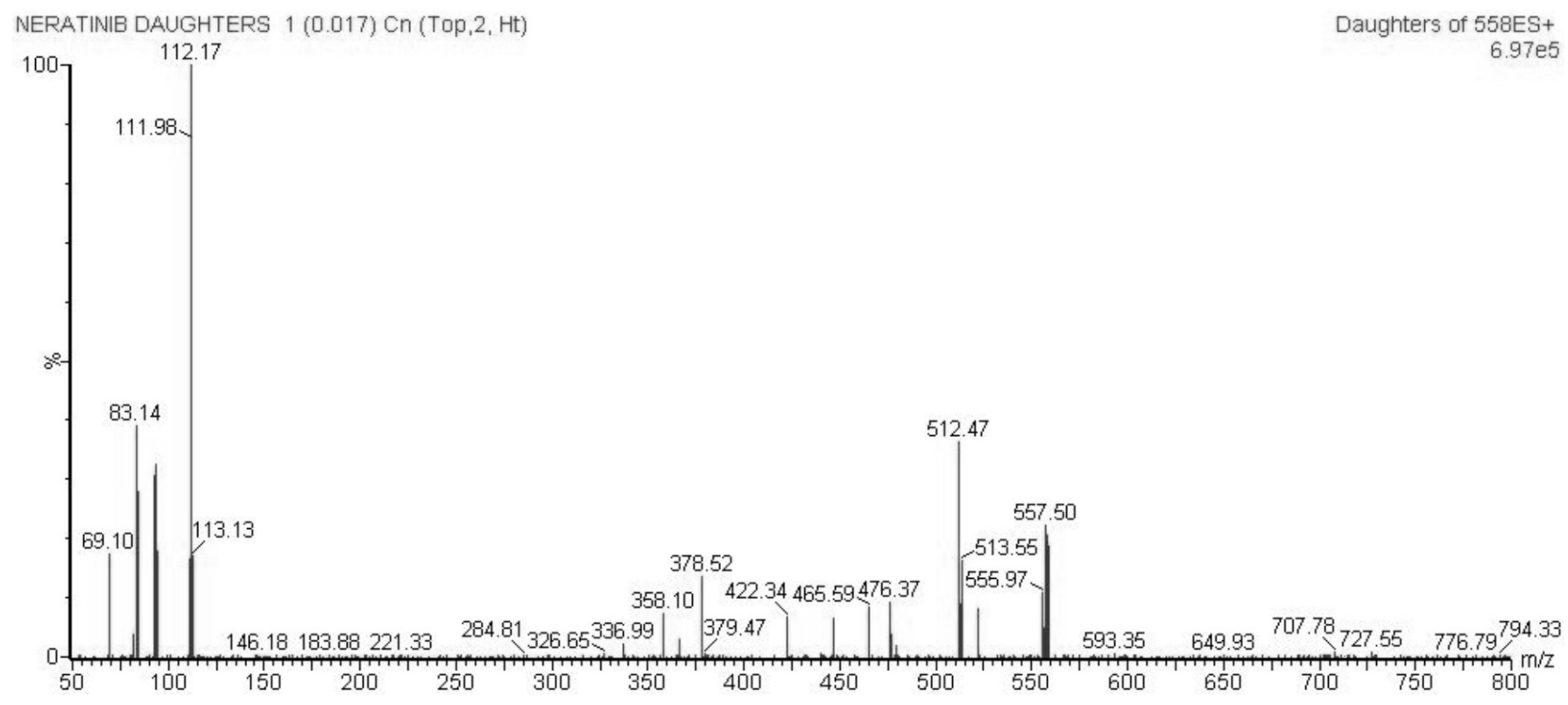

Figure 1 The product ion spectra of neratinib. 
the weighting factor using least-squares linear regression. Back calculations from these curves were used to determine NTB concentrations in the calibration standard solutions and to determine the concentrations of the analyte. To determine the accuracy and precision of the method QC samples at four different concentration levels $4 \mathrm{ng} \mathrm{mL} \mathrm{m}^{-1}$ lower limit of quantitation (LLOQ), $12 \mathrm{ng} \mathrm{mL}^{-1}$ low quality control (LQC), $200 \mathrm{ng} \mathrm{mL}^{-1}$ middle quality control (MQC) and $400 \mathrm{ng} \mathrm{mL}^{-1}$ high quality control $(\mathrm{HQC})$ were used. On three different days $(n=6)$ the QC concentration level were quantified with seperate calibration curves. The accuracy and the precision for each QC level was evaluated by calculating the recovery percent and relative standard deviation (RSD) of the measured concentrations, respectively. The accuracy was within $\pm 15 \%$ and the precision, (intraand inter-day) was required to be less than $15 \%$. Extraction recovery for NTB in spiked plasma samples $(n=6)$ was estimated by comparing peak area of neratinib in different $Q C$ concentrations (LQC, MQC and HQC) to extracted drug-free plasma peak area spiked with the same amount of NTB preceding chromatographic analysis. Extraction recovery for IS $(n=6)$ was determined in a similar way as for the QC samples. The matrix effect can cause either ion suppression or ion enhancement. ${ }^{28}$ For NTB the effect was evaluated by comparing the peak areas for extracted drug free plasma QC samples (LQC, MQC and HQC) to the peak area of neat solvent spiked with similar concentration. The bench top stability of the NTB was studied in plasma at room temperature for $6 \mathrm{~h}$. QC samples were kept in an autosampler for $48 \mathrm{~h}\left(8^{\circ} \mathrm{C}\right)$ to determine the stability of the compound during analysis. The stability over three freeze-thaw cycles was evaluated for the QC samples stored at $-80^{\circ} \mathrm{C}$ for plasma. Determination of long-term stability was carried out by storing test samples at around $-80^{\circ} \mathrm{C}$ for 60 days. Stock solution stability for NTB in methanol was determined at $25^{\circ} \mathrm{C}$ for $24 \mathrm{~h}$ and also in refrigerated condition $\left(4-8^{\circ} \mathrm{C}\right)$ for 30 days prior to chromatographic analysis. Dilution integrity was carried out for NTB to evaluate effect of dilution on concentration above ULOQ as some samples may need dilution during real time samples analysis.

\section{Results and Discussion}

\subsection{Chromatographic Conditions Optimization}

$100 \mathrm{ng} \mathrm{mL}^{-1}$ of NTB and the IS were used for the tuning of the mass spectrometer in positive ionization mode with ESI as the ionization source. The MS parameters were optimized for quantification of NTB and IS and these parametes comprised the ESI source temperature, capillary, collision energy and cone voltage, flow rate of cone gas, desolvation temperature and gas. The most important parameters amongst them were collision energy and cone voltage. Cone voltage (2-100) V and collision energies (2-80) eV ramp were used to determine the optimum cone voltage and collision energy and were found out to be $46 \mathrm{~V}$ and $30 \mathrm{eV}$, respectively for $m / z 557.51 \rightarrow 112.17$ transition. The optimum cone voltage and collision energy using ramp for the IS, $450.0 \rightarrow 260.0$ transition were found out to be of $48 \mathrm{~V}$ and $28 \mathrm{eV}$, respectively.

\subsection{Optimization of Sample Processing}

Sample preparation was performed using the protein precipitation technique (PPT) ${ }^{28}$. PPT can be helpful in producing clean samples as these are a requisite in order to avoid endogenous substances from interfereing with the analysis and functioning of LC and MS/MS systems. Clean samples are also important for minimizing ion suppression and matrix effects.

\subsection{Selectivity}

For assessing the selectivity of the method, chromatograms of blank plasma were compared with the corresponding spiked LLOQ samples. Blank human plasma samples (six different batches) were analyzed to establish the peaks which may be due to the likely biological plasma constituents. For determination of NTB and IS in plasma the method was found to be selective. As is evident from Fig. 2A and Fig. 2B, blank plasma did not show any interference at the analyte and IS retention time. LLOQ and LQC chromatograms are represented in Fig. 2C and Fig. 2D, and Fig. 2E and Fig. 2F represent HQC and IS chromatograms.

\subsection{Linearity and Sensitivity}

Calibration curves for NTB in human plasma were generated using area ratio of (NTB/IS) as a function of NTB concentration. Determination coefficients $\left(r^{2}\right)$ during the course of validation was found to be greater than 0.996 . Linearity of the method was found to be $4-500 \mathrm{ng} \mathrm{mL}^{-1}$. LLOQ of $4 \mathrm{ng} \mathrm{mL}^{-1}$ of NTB in plasma was adequate for investigation of its pharmacokinetic behaviour.

\subsection{Accuracy and Precision}

The inter- and intra-day accuracy and precision values for QC samples are presented in Table 1. The intra- and inter- day (\% CV) values for plasma were $4.29-10.99 \%$ and $2.71-7.39 \%$, respectively, and these values are within the range of tolerable limits ${ }^{26,27}$ for precision and accuracy.

\subsection{Recovery}

The extraction recoveries for NTB at the LQC, MQC and HQC are presented in Table 2 . The extraction recovery for NTB (mean \pm S.D.) was $69.12 \pm 3.58 \%$ and for the IS (crizotinib) the mean recovery at the concentration tested was $85.19 \pm 9.64 \%$. Although, this extraction recovery was relatively low, the sensitivity of PPT with methanol and acetonitrile as sample pre-treatment was adequate, since the desired LLOQ for all

Table 1 Intra- and inter-day precision and accuracy of NTB in human plasma.

\begin{tabular}{|c|c|c|c|c|}
\hline $\begin{array}{l}\text { Spiked conc. } \\
\text { /ng mL } \mathrm{mL}^{-1}\end{array}$ & Run & $\begin{array}{l}\text { Measured conc. } \\
/ \mathrm{ng} \mathrm{mL}^{-1} \pm \text { S.D. }\end{array}$ & $\begin{array}{l}\text { Precision } \\
(\text { RSD/\%) }\end{array}$ & $\begin{array}{c}\text { Accuracy } \\
\text { (recovery/\%) }\end{array}$ \\
\hline
\end{tabular}

Intraday variation (six replicate at each concentration)

\begin{tabular}{lrrrr}
\hline 4 & 1 & $4.31 \pm 0.38$ & 8.82 & 107.75 \\
& 2 & $3.82 \pm 0.42$ & 10.99 & 95.50 \\
12 & 3 & $4.39 \pm 0.42$ & 9.57 & 109.75 \\
\hline 200 & 1 & $11.85 \pm 1.16$ & 9.79 & 98.75 \\
& 2 & $12.51 \pm 0.96$ & 7.67 & 104.25 \\
& 3 & $12.21 \pm 1.03$ & 8.44 & 101.75 \\
\hline 400 & 1 & $188.25 \pm 13.25$ & 7.04 & 94.12 \\
& 2 & $196.21 \pm 11.12$ & 5.67 & 98.10 \\
& 3 & $212.39 \pm 15.98$ & 7.52 & 106.19 \\
\hline & 1 & $423.38 \pm 18.15$ & 4.29 & 105.84 \\
& 2 & $403.85 \pm 22.73$ & 5.63 & 100.96 \\
& 3 & $390.25 \pm 19.86$ & 5.09 & 97.56 \\
\hline
\end{tabular}

Interday variation (18 replicates at each concentration)

\begin{tabular}{lccr}
\hline 4 & $4.17 \pm 0.31$ & 7.39 & 104.33 \\
12 & $12.19 \pm 0.33$ & 2.71 & 101.58 \\
200 & $198.95 \pm 12.30$ & 6.18 & 99.48 \\
400 & $405.83 \pm 16.65$ & 4.10 & 101.46 \\
\hline
\end{tabular}



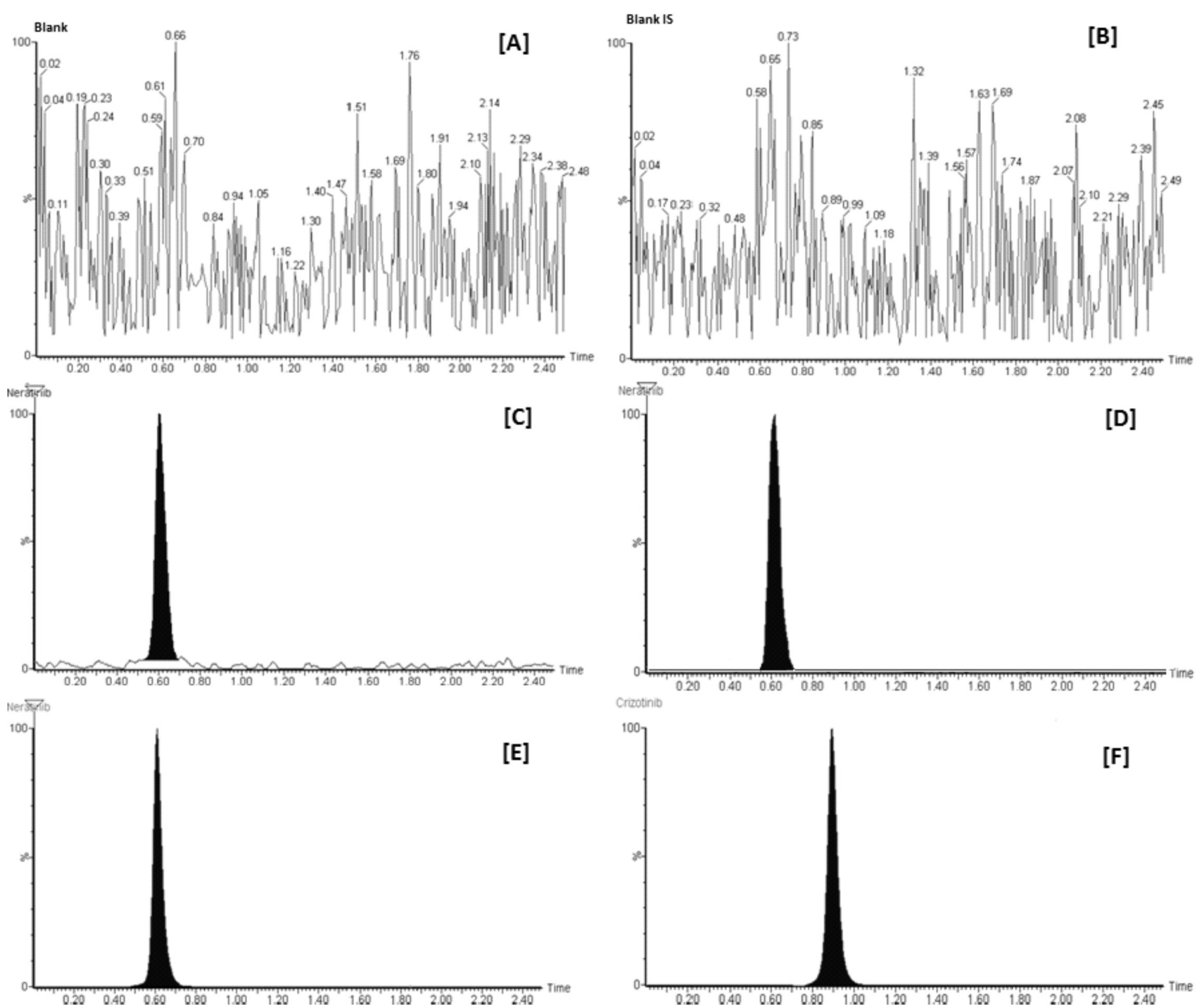

Figure 2 Retention time of analyte and IS in the blank plasma are shown in A and B respectively. C and D, represent chromatogram of LLOQ and LQC, whereas representative chromatogram HQC and IS are shown in E and F, respectively.

analytes were achieved with a $\mathrm{S} / \mathrm{N}>10$. Moreover, the robustness of this sample pre-treatment method was sufficient ${ }^{26}$ with $\mathrm{CV}$ values $<8.39 \%$ over the entire concentration range. Protein precipitation seemed to be a fast and simple one-step sample pre-treatment procedure for the analysis of NTB in plasma.

\subsection{Matrix Effect}

Three different lots of plasma were evaluated at each QC level (LQC,MQC and HQC) and per cent nominal concentrations with RSD. were observed to be $(91.11 \pm 1.85 \%, 83.26 \pm 1.77 \%$, and $85.64 \pm 1.07 \%$, respectively). A similar analysis was performed

Table 2 Recovery data of NTB (three QC samples) and crizotinib in human plasma

\begin{tabular}{lcc}
\hline Compound & Spiked conc./ng mL & Recovery $/ \% \pm$ S.D. \\
\hline NTB (analyte) & 12 & $65.30 \pm 8.39$ \\
& 200 & $69.65 \pm 6.28$ \\
Mean \pm S.D. & 400 & $72.41 \pm 6.19$ \\
Crizotinib (IS) & 50 & $69.12 \pm 3.58$ \\
\hline
\end{tabular}

for the IS and the per cent nominal concentration with RSD. was $(93.27 \pm 2.65 \%)$. The results indicate that ion suppression or enhancement from plasma matrix was consistent for this analytical method and would not interfere in the measurement of the analytes.

\subsection{Stability}

NTB spiked plasma samples were quite stable at $25{ }^{\circ} \mathrm{C}$ for a period of $6 \mathrm{~h}$, in the autosampler at $8{ }^{\circ} \mathrm{C}$ for a period of $48 \mathrm{~h}$, during three freeze-thaw cycles and for 60 days at $-80{ }^{\circ} \mathrm{C}$. The stock solution of NTB and IS were also stable for a period of period of 30 days at $\left(4-8{ }^{\circ} \mathrm{C}\right)$ (Table 3$)$.

\subsection{Dilution Integrity}

As indicated in Table 3 the dilution integrity was maintained after 2 and 4 times dilution and hence does not effect the analysis of NTB in plasma.

\section{Conclusion}

A UPLC-MS/MS method for estimation of NTB in human plasma was developed and validated. In all the documented references, no method has been reported for the determination 
Table 3 Stability and dilution integrity data of Neratinib

\begin{tabular}{|c|c|c|c|c|c|}
\hline Stability & & $\begin{array}{l}\text { Spiked conc. } \\
\text { /ng mL }\end{array}$ & $\begin{array}{l}\text { Measured conc. } \\
\text { /ng mL } \mathrm{mL}^{-1} \pm \text { S.D. }\end{array}$ & $\begin{array}{l}\text { Precision } \\
\text { (RSD/\%) }\end{array}$ & $\begin{array}{c}\text { Accuracy } \\
\text { (recovery/\%) }\end{array}$ \\
\hline & Bench top (6h) & $\begin{array}{r}12 \\
400\end{array}$ & $\begin{array}{c}11.83 \pm 0.98 \\
391.28 \pm 12.56\end{array}$ & $\begin{array}{l}8.28 \\
3.20\end{array}$ & $\begin{array}{l}98.58 \\
97.82\end{array}$ \\
\hline & Freeze thaw ( 3 cycles) & $\begin{array}{r}12 \\
400\end{array}$ & $\begin{array}{c}12.62 \pm 1.02 \\
383.89 \pm 17.85\end{array}$ & $\begin{array}{l}8.08 \\
4.64\end{array}$ & $\begin{array}{r}105.16 \\
95.97\end{array}$ \\
\hline & Auto sampler (48 h) & $\begin{array}{r}12 \\
400\end{array}$ & $\begin{array}{c}12.37 \pm 0.54 \\
406.71 \pm 10.25\end{array}$ & $\begin{array}{l}4.36 \\
2.52\end{array}$ & $\begin{array}{l}103.08 \\
101.67\end{array}$ \\
\hline & 30 days at $\pm 80^{\circ} \mathrm{C}$ & $\begin{array}{r}12 \\
400\end{array}$ & $\begin{array}{c}11.59 \pm 0.69 \\
411.46 \pm 21.35\end{array}$ & $\begin{array}{l}5.95 \\
5.18\end{array}$ & $\begin{array}{r}96.58 \\
102.86\end{array}$ \\
\hline & Dilution integrity & $\begin{array}{l}200 \\
400\end{array}$ & $\begin{array}{l}212.32 \pm 15.48 \\
420.13 \pm 25.18\end{array}$ & $\begin{array}{l}7.29 \\
5.99\end{array}$ & $\begin{array}{l}106.16 \\
105.03\end{array}$ \\
\hline
\end{tabular}

and validation of NTB using UPLC-MS/MS in human plasma. The method was highly sensitive with high-throughput. Samples were prepared by using simple PPT and each sample had a run time of 2 min only. The developed method will be useful for pharmacokinetic and toxicokinetic analysis of NTB in humans.

\section{Conflict of interest}

The authors declare that there is no conflict of interest.

\section{Acknowledgements}

The authors would like to extend their appreciation to the Deanship of Scientific Research at King Saud University for its funding of this research through the research group project No. RG-1435-073.

\section{References}

1 J. Schlessinger, Cell signaling by receptor tyrosine kinases, Cell, 2000, $103,211-225$

2 S.K. Rabindran Antitumor activity of HER-2 inhibitors, Cancer Lett., 2005, 227, 9-23.

3 R. Abbas, B.A. Hug, C. Leister, J. Burns and D. Sonnichsen, Pharmacokinetics of oral neratinib during co-administration of ketoconazole in healthy subjects Br. J. Clin. Pharmacol. 2011, 71, 522-527.

4 D.J. Slamon, G.M. Clark, S.G. Wong, W.J. Levin, A. Ullrich and W.L. McGuire, Human breast cancer: correlation of relapse and survival with amplification of the HER-2/neu oncogene, Science, 1987, 235, 177-182.

5 M.A. Cobleigh, C.L. Vogel, D. Tripathy, N.J. Robert, S. Scholl, L. Fehrenbacher, J.M. Wolter, V. Paton, S. Shak, G. Lieberman and D.J. Slamon, Multinational study of the efficacy and safety of humanized anti-HER2 monoclonal antibody in women who have HER2-overexpressing metastatic breast cancer that has progressed after chemotherapy for metastatic disease. J. Clin. Oncol., 1999, 17, 2639-2648.

6 D.J. Slamon, B. Leyland-Jones, S. Shak, H. Fuchs, V. Paton, A. Bajamonde, T. Fleming, W. Eiermann, J. Wolter, M. Pegram, J. Baselga and L. Norton, Use of chemotherapy plus a monoclonalantibody against HER2 for metastatic breast cancer that overexpresses HER2. N. Engl. J. Med., 2001, 344, 783-792.

7 HERCEPTIN ${ }^{\circledR}$ (trastuzumab) (United States package insert). San Francisco, CA: Genentech, 2008

8 S.K. Rabindran, C.M. Discafani, E.C. Rosfjord, M. Baxter, M.B. Floyd J. Golas, W.A. Hallett, B.D. Johnson, R. Nilakantan, E. Overbeek, M.F. Reich, R. Shen, X. Shi, H.R. Tsou, Y.F. Wang and A. Wissner, Antitumor activity of HKI-272, an orally active, irreversible inhibitor of the HER-2 tyrosine kinase, Cancer Res., 2004, 64, 3958-3965.

9 H.R. Tsou, E.G. Overbeek-Klumpers, W.A. Hallett, M.F. Reich, M.B. Floyd, B.D. Johnson, R.S. Michalak, R. Nilakantan, C. Discafani, J. Golas, S.K. Rabindran, R. Shen, X. Shi, Y.F. Wang, J. Upeslacis and A. Wissner, Optimization of 6,7-disubstituted-4-(arylamino)quino- line-3-carbonitriles as orally active, irreversible inhibitors of human epidermal growth factor receptor-2 kinase activity, J. Med. Chem., 2005, 48, 1107-1131.

10 A. Wissner and T.S. Mansour, The development of HKI-272 and related compounds for the treatment of cancer. Arch. Pharm., 2008, $341,465-477$.

11 H. J. Burstein, Y. Sun and A.R. Tan, Neratinib (HKI-272), an irreversible pan erbB receptor tyrosine kinase inhibitor: phase 2 results in patients with advanced HER2+ breast cancer. Cancer Res., 2009, 69 (suppl. 2), 37.

12 R. Swaby, K. Blackwell, Z. Jiang, Y. Sun, V. Dieras, K. Zaman and M. Thakuria, Neratinib in combination with trastuzumab for the treatment of advanced breast cancer: a phase I/II study. J. Clin. Oncol., 2009, 27(15S), 1004.

13 K.K. Wong, P.M. Fracasso, R.M. Bukowski, T.J. Lynch, P.N. Munster, G.I. Shapiro, P.A. Janne, J.P. Eder, M.J. Naughton, M.J. Ellis, S.F. Jones, T. Mekhail, C. Zacharchuk, J. Vermette, R. Abbas, S. Quinn, C. Powell and H.A. Burris, A phase I study with neratinib(HKI-272), an irreversible pan ErbB receptor tyrosine kinase inhibitor, in patients with solid tumors, Clin. Cancer. Res., 2009, 15, 2552-2558.

14 A. Bottle, C. Tsang, C. Parsons, A. Majeed, M. Soljak and P. Aylin, Association between patient and general practice characteristics and unplanned first-time admissions for cancer: observational study, $\mathrm{Br}$. J. Cancer, 2012, 107,1213-1219

15 P. Bose and H. Ozer, Neratinib: an oral, irreversible dual EGFR/ HER2 inhibitor for breast and non-small cell lung cancer, Expert Opin. Investig. Drugs, 2009, 18, 1735-1751.

16 D. Gajria and S. Chandarlapaty, HER2-amplified breast cancer: mechanisms of trastuzumab resistance and novel targeted therapies, Expert Rev. Anticancer Ther., 2011, 11, 263-275.

17 R. Abbas, B.A. Hug, C. Leister, J. Burns and D. Sonnichsen, Singleascending-dose (sad) study of safety, tolerability, and pharmacokinetics (pk) of hki-272 in healthy subjects. AAPS J., 2009, 11, abstract-906.

18 R. Abbas, B.A. Hug, C. Leister, J. Burns and D. Sonnichsen, Pharmacokinetics of oral neratinib during co-administration of ketoconazole in healthy subjects, Br. J. Clin. Pharmacol., 2011, 71, 522-527.

19 T.A. Wani, N.Y. Khalil, I. Darwish, M. Iqbal and A.H. Bakheit, Highly sensitive and simple validated ultra-performance liquid chromatography/tandem mass spectrometry method for the determination of cinacalcet in human plasma, Curr. Pharmaceut. Anal., 2014, 10, 51-57.

20 R. Russo, D. Guillarme, T.T.N.D.C. Bicchi, S. Rudaz and J.L. Veuthey, Pharmaceutical applications on columns packed with sub-2 microm particles, J. Chromatogr. Sci., 2008, 46, 199-208.

21 D.T. Nguyen, D. Guillarme, S. Rudaz and J.L. Veuthey, Fast analysis in liquid chromatography using small particle size and high pressure, J. Sep. Sci., 2006, 29, 1836-1848.

22 T.A. Wani, Highly sensitive ultra-performance liquid chromatography-tandem mass spectrometry method for the determination of abiraterone in human plasma, Analyt. Methods, 2013, 5, 3693-3699.

23 A. de Villiers, F. Lestremau, R. Szucs, S. Gelebart, F. David and P. Sandra, 
Evaluation of ultra performance liquid chromatography. Part I. Possibilities and limitations, J. Chromatogr. A, 2006, 1127, 60-69.

24 S.A. Wren and P. Tchelitcheff, Use of ultra-performance liquid chromatography in pharmaceutical development. J. Chromatogr. A, 2006, 1119, 140-146.

25 L. Novakova, L. Matysova and P. Solich, Advantages of application of UPLC in pharmaceutical analysis, Talanta, 2006, 68, 908-918.

26 US Food and Drug Administration, Center for Drug Evaluation and
Research (CDER). Guidance for industry, Bioanalytical Method Validation. 2001 http://www.fda.gov/downloads/Drugs/.../ Guidances/ucm070107.pdf

27 European Medicines Agency, Guideline on bioanalytical method validation. 2011. http://www.ema.europa.eu/docs/en_GB/document library/Scientific_guideline/2011/08/WC500109686.pdf

28 S. Mitra and R. Brukh, Sample preparation: an analytical perspective. In: Sample Preparation Techniques in Analytical Chemistry, (S. Mitra, ed.), John Wiley \& Sons, Inc, USA, 2003, pp. 1-36. 